

\title{
DESIGN OF AN AIRBORNE LAUNCH VEHICLE AND AN AIR LAUNCHED SPACE BOOSTER
}

\author{
Stefan M. Poth, Jr.* \\ Michael A. Fisher ** \\ David W. Levy ${ }^{\dagger}$ \\ Joe G. Eisley ${ }^{\ddagger}$ \\ University of Michigan \\ Department of Aerospace Engineering \\ Ann Arbor, Michigan
}

\begin{abstract}
A conceptual design is presented for an air launched space booster and an associated carrier vehicle. This system is capable of placing $17,000 \mathrm{lbs}$ in low earth orbit (LEO) and 7,900 lbs in geosynchronous transfer orbit (GTO). The airplane features a twin fuselage configuration for improved payload and landing gear integration, a high aspect ratio wing for high lift and maneuverability at altitude, and is powered by six engines. The aircraft weighs approximately 1.2 million pounds at take off. It releases the booster at approximately 43,000 feet. The booster weighs just under $500,000 \mathrm{lbs}$ and has three stages. A primary design goal was to have launch costs well below those of competitive launch systems; thus, off the shelf technology has been used throughout.
\end{abstract}

\section{Introduction}

One way of reducing the total weight of a space booster for a given payload weight is to launch the booster from an airplane. Among the advantages are that the kinetic and potential energy of the airplane are added to that of the space booster and the launch takes place above a substantial portion of the atmosphere so that aerodynamic drag is reduced. One current design which takes advantage of this approach is the Pegasus, manufactured by Orbital Sciences Corporation. The Pegasus has a total weight of 41,000 pounds and a payload weight of 900 pounds. It has been carried aloft and launched by a Boeing B-52 and future launches are planned from a modified Lockheed L-1011.

\footnotetext{
* Undergraduate Student, Aerospace Engineering, AIAA Student Member

** Undergraduate Student, Aerospace Engineering

$\dagger$ Lecturer, Aerospace Engineering; currently Aerodynamics Engineer, Cessna Aircraft Company, ALAA Senior Member

$\ddagger$ Professor, Aerospace Engineering, AIAA Associate Fellow
}

In the future, there may be a market for an air launched space booster an order of magnitude larger. A space booster of this size would be capable of placing a heavy payload into low earth orbit (LEO), say, for space station resupply or one or more satellites into geosynchronous transfer orbit (GTO). Such a large booster would require a new airplane to be purposely built for its launch since no current airplane could carry a space booster of this size to any significant altitude.

\section{Class History and Interactions}

In the fall of 1992, the University of Michigan AE 481 Airplane Design class undertook the design of an airplane to carry a large air launched space booster. A preliminary design was formulated by each of the 35 students in the class. The space booster weight was set arbitrarily at 250,000 pounds as a base for a feasibility study. The class then split into two groups to continue the design process, with one group pursuing a conventional design and the other group pursuing a more unusual twin fuselage design. The payload capacity was increased to 500,000 pounds when the individual design projects proved that to be a feasible goal.

In the winter term, seven students elected to continue this design project under AE 490/590 Advanced Airplane Design, a directed study class with the goal of presenting a more fully defined design at the Universities Space Research Association (USRA) Advanced Design Program (ADP) Annual Conference in Houston in June 1993. Simultaneously 40 students in AE 483 Space System Design began the design of a $500,000 \mathrm{lb}$ booster to be used with the evolving airplane. The two classes coordinated their work through the end of the winter term. After evaluating a conventional airplane design with the payload suspended beneath the fuselage and, briefly a flying wing, the final configuration chosen was a twin fuselage airplane with the space booster suspended beneath the center wing. It proved by far the best for landing gear arrangement and payload integration with the booster that was being developed in the AE 483 class. 


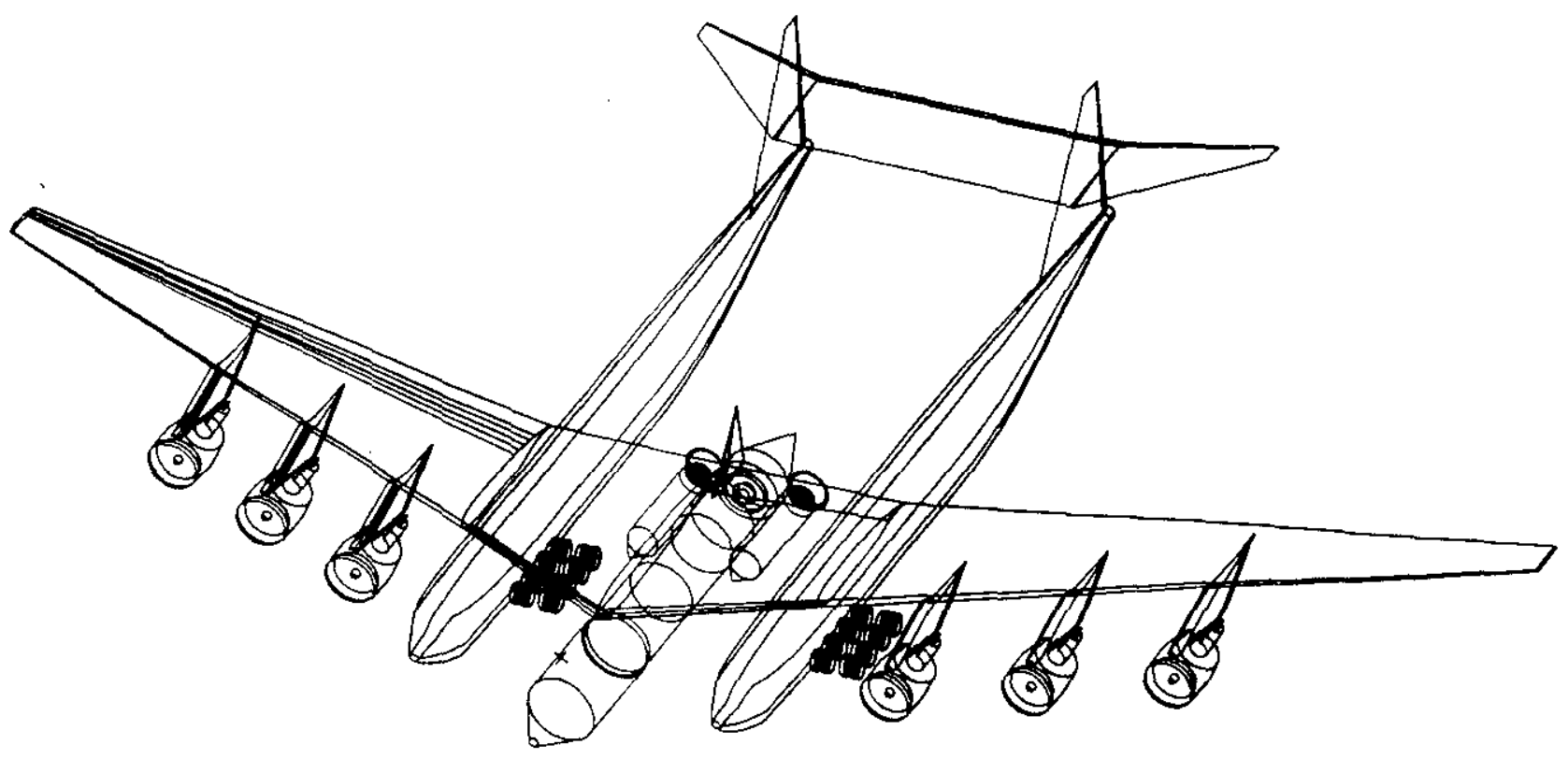

Fig. 1. System Configuration.

The booster size and configuration were driven by the performance and size of existing rocket engines. In early attempts the $A E 483$ class tried for an all solid fuel system; however, it proved impossible to achieve. The final booster design uses three different rocket engines and three different fuels.

\section{Overview}

Mission requirements include:

Aircraft

- mission radius of 750 statute miles

- launch altitude of at least 40,000 feet

- the ability to use existing airport facilities

- the ability to perform $2.2 \mathrm{~g}$ post-launch maneuver at altitude

\section{Booster}

- 17,000 lbs in LEO consistent with the requirements for space station resupply

- 7,900 lbs in GTO consistent with the requirements of typical communications satellites

\section{System}

- reliance on components, subsystems, and processes currently used in production or which will be in the very near future

- commercially competitive launch costs

- safety in assembly, handling, and launching

- near term delivery of complete system

Market studies concluded that six launch missions per year would be a realistic design goal. A ten year life span for the launch system is anticipated as this would reach until the introduction of the next planned launch systems. Only two airplanes would be built. The first would be a fully functional aircraft while the second would act as a structural spare.

The final configuration of the system is presented in Figure 1.

Some of the important parameters are tabulated in Table 1. The twin fuselage configuration of the airplane, from now on called the Eclipse, allows for straightforward payload and landing gear integration. The high aspect ratio wing was necessitated by the need for controlled flight at high altitude. There are six GE-90 engines to provide the thrust needed to attain altitude. Two vertical tails are positioned with the horizontal tail between them in a cruciform layout. This configuration keeps the tails out of the wake of the wing, payload, and engines while keeping the horizontal tail below an area susceptible to deep stall.

The booster, from now on called the Gryphon, consists of three stages for the GTO configuration. For the LEO configuration the third stage is removed and replaced with pure payload. The major components are shown in Figure 2. The first stage consists of two Castor 120 solid fueled engines attached to the sides and one LR-91 in the main body using storable liquid fuel. The second stage has two LR-91 engines and the third stage one RL10A-4 using cryogenic fuel.

Full details on the Eclipse and the Gryphon are provided in the two USRA ADP final reports. 1,2 


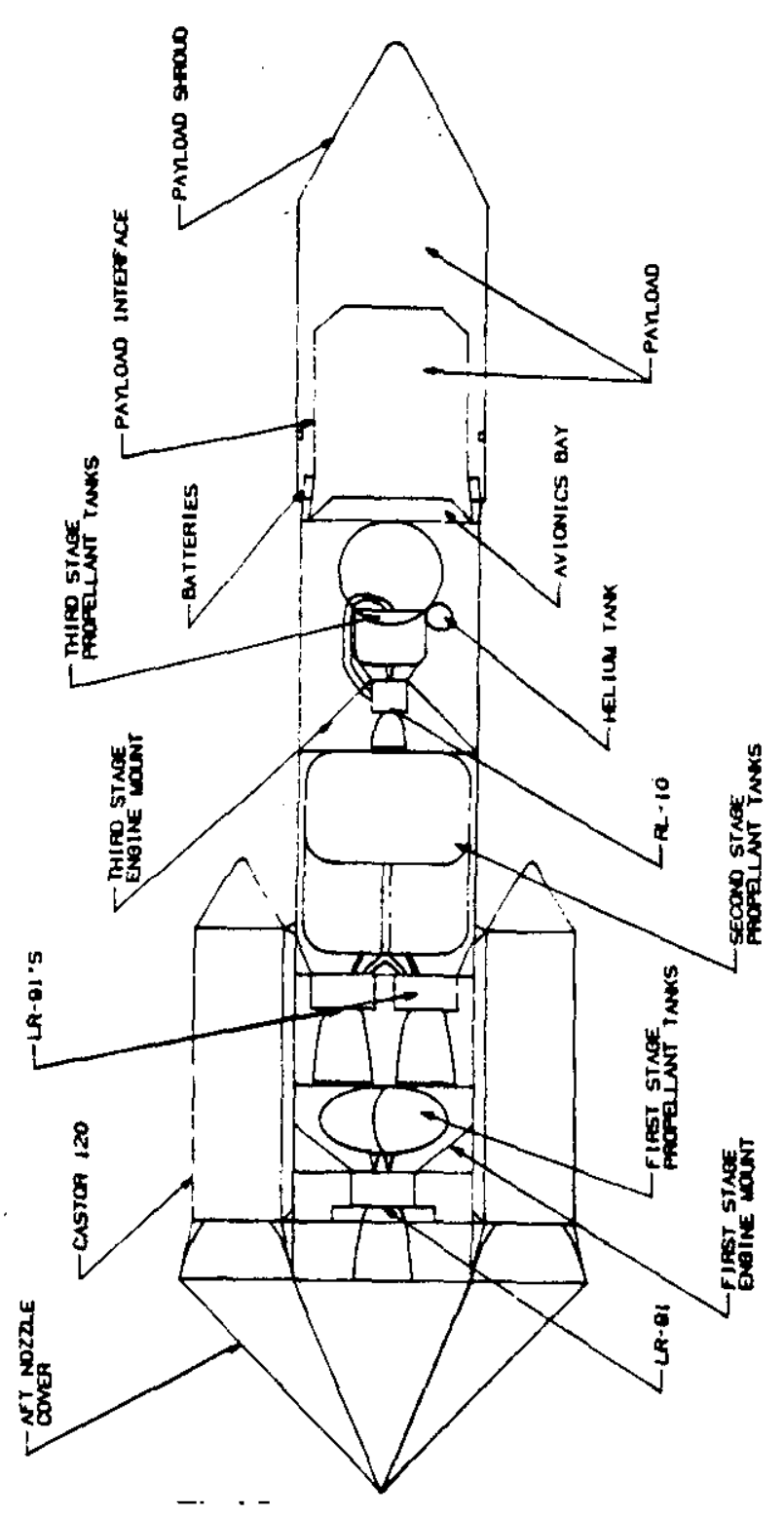

Fig. 2. Booster Internal Components.

\section{Mission Profile and Trajectory}

The design mission profile for the system is shown in Figure 3. The aircraft takes off and climbs to an efficient cruise altitude and cruises for up to 750 miles to an predetermined launch location. Upon approaching the launch site after a short loiter it drops the booster at 43,300 feet. It immediately turns away to clear the space for the booster, retums to cruise altitude, and returns to base.

The Gryphon is dropped from the Eclipse at 43,300 feet and during an ensuing 10 second drop the aerodynamic shape causes a 20 degree pitchup. At this time the first stage engines ignite and a pitch rate of 6.25 degrees per second is obtained by gimballing the engine nozzles until the pitch angle reaches 10 degrees from the vertical. The
Gryphon pitches back down before the second stage ignition to an angle of 70 degrees from the vertical.

The first stage engines burnout at 130,397 feet and a velocity of 7,297 feet per second. Second stage ignition accelerates the Gryphon to a circular parking orbit at 574,240 feet altitude and a velocity of 24,864 feet per second. The payload shroud is jettisoned along the way at an altitude of 200,000 feet. Once the parking orbit is reached the second stage is ejected and the Gryphon orbits until it reaches the proper position for insertion in GTO. Finally, the third stage ignites and GTO insertion is completed.

Table 1. Eclipse Parameters.
Take off weight

Payload weight (U. of Mich. Gryphon)

Fuel weight (including ramp fuel)

Operational weight empty

Wing area

Wing span

Overall length

Overall height

Take off thrust (w/o extractions)

Thrust-to-weight ratio

Take off field length (to $35 \mathrm{ft}$ )

Landing field length (from $35 \mathrm{ft}$ )

Wing aspect ratio

Wing quarter chord sweep angle

Wing loading

Vertical tail area (each)

Horizontal tail area

Cruise velocity

Launch altitude (design mission)

$$
\begin{array}{r}
1,227,000 \mathrm{lbf} \\
479,000 \mathrm{lbf} \\
241,000 \mathrm{lbf} \\
541,000 \mathrm{lbf} \\
11,750 \mathrm{ft}^{2} \\
368 \mathrm{ft} \\
188.6 \mathrm{ft} \\
62.4 \mathrm{ft} \\
600,000 \mathrm{lbf} \\
0.489 \\
4,300 \mathrm{ft} \\
3,400 \mathrm{ft} \\
11.53 \\
22.1^{\circ}
\end{array}
$$

$104.4 \mathrm{lbf} / \mathrm{ft}^{2}$

$950 \mathrm{ft}^{2}$

$3700 \mathrm{ft}^{2}$

$515 \mathrm{mph}$ $43,300 \mathrm{ft}$

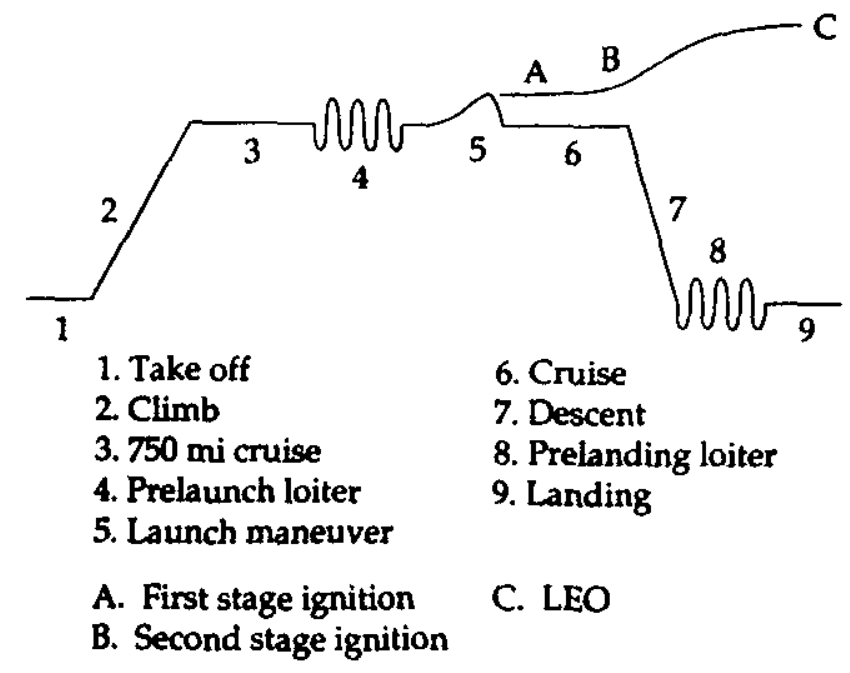

Fig. 3. Airborne Mission Profile. 


\section{Propulsion}

The engine selected for the Eclipse is a planned growth version of the General Electric GE-90 which will be rated at 100,000 pounds take off thrust. Six of these engines will be used to provide the thrust needed to attain altitude. The growth version of the GE-90 was selected because it is the only engine which will be commercially available in the near future which meets the thrust requirements for this airplane. The high lapse rate of thrust with altitude makes the airplane highly overpowered at take off and during a large portion of the climb. Thrust specific fuel consumption and uninstalled thrust available (including ram drag) data was supplied by the manufacturer. ${ }^{3}$ Installed thrust levels were obtained using empirical models for estimating extractions. ${ }^{4}$

Nacelles were sized using semi-empirical methods based on experience and wind tunnel testing. 5 The engines are located with a diameter and a quarter between each engine and from the fuselage. They are mounted below and in front of the wing. This location was chosen to minimize the losses associated with installation and therefore improve altitude performance.

Various combinations of existing rocket engines and staging were studied. Those identified in Table 2 were rejected for the reasons shown.

Table 2. Rejected Configurations.

\begin{tabular}{ll}
\hline Configuration & Drawback \\
\hline All solid fuel & Not enough payload, Too heavy \\
No cryogenic fuels & Not enough payload, Too heavy \\
Cryogenic Stage 2 & Safety concerns \\
Extra Stage & Too expensive \\
\hline
\end{tabular}

The configuration finally selected is identified in Table 3.

Table 3. Propulsion Configuration

\begin{tabular}{lll}
\hline Stage & System & Fuel \\
\hline 1 & 2 Castor 120 & Solid \\
1 & 1 LR91-AJ-11 & Storable liquid \\
2 & 2 LR91-AJ-11 & Storable liquid \\
3 & 1 RL10A-4 & Cryogenic liquid \\
\hline
\end{tabular}

This final design meets the payload and cost goals originally selected.

\section{Airplane Aerodynamics}

The wing airfoil is a NASA 14-percent thick supercritical airfoil. 6 A supercritical airfoil was chosen to minimize wave drag and therefore increase cruise speed. To further increase the critical Mach number, the wing has a leading edge sweep of $25^{\circ}$. This raises the critical Mach number to 0.78 , or roughly the cruise speed of the airplane. The vertical tails are NACA 0012 airfoils while the horizontal tail is a NACA 0008 airfoil for the inboard section, to raise critical Mach number where there is no leading edge sweep, and a NACA 0010 airfoil outboard of the vertical tails. The outboard sections have a leading edge sweep of $40^{\circ}$. This results in a higher critical Mach number for the horizontal tail than the wing, as required for stability and control purposes.

Drag polars for the airplane were found using semiempirical methods. ${ }^{4}$ Along with this, the interference drag from the payload, i.e. the space booster, was accounted for by adding ten percent of the wing drag to the area which is directly affected by the flow around the payload. An additional five percent is added to the final drag number to account for interference in the rest of the airplane. ${ }^{7}$

A single slotted Fowler flap with an area of $1346.4 \mathrm{ft}^{2}$, covering 30 percent of the chord and from 23 to 32 and 38 to 70 percent of the half span, is utilized to lower the take off and landing speed to acceptable levels. No leading edge devices are employed. For take off, $\mathrm{C}_{\mathrm{L} \max }=2.06$ with a flap deflection of $20^{\circ}$ and for landing, $C_{L \text { max }}=$ 2.65 with a flap deflection of $45^{\circ}$.

\section{Structures \& Weights}

A V-n diagram was constructed to determine the loads acting on the aircraft during flight. Between the maneuver load and gust induced load plots, the maximum loads on the airplane can be deduced. These showed a limit load of $2.5 \mathrm{~g}$ which implies, with a factor of safety of 1.5 , a ultimate load of $3.75 \mathrm{~g}$.

The majority of component weights for the airplane were found using semi-empirical methods. 8 These values were calibrated using a production aircraft part of similar dimensions and configuration. Engine and nacelle weights were supplied by General Electric. ${ }^{3}$ Wing weight was calculated using an analytical method developed specifically for twin fuselage aircraft. ${ }^{9}$ This method calculates the structure required to resist the shear and bending moments associated with the distributed and point loads acting on the wing. Semi-empirical models are then used to give weights for non-load bearing surfaces and trailing edge devices. The analytical method results in a wing group weight percentage of gross take off weight which is in line with that of current production airplanes.

The longitudinal center of gravity was calculated by assigning each component a center of gravity and then calculating the weighted average. All measurements are made from a reference datum 50 feet in front of the forward most point of the wing. The payload and fuel centers of 
gravity are collocated with the airplane center of gravity to minimize center of gravity shifts during the flight and launch maneuver.

The Gryphon uses conventional booster stuctural design concepts. In general each stage has the following:

- Engine mounts

- Propellant tank supports

- Interstage connections

- External skin with reinforcements

Ease of manufacture and assembly were primary concerns throughout.

Actual weights of engines, propellant tanks and other components from existing systems were used. Detailed design and structural analysis of engine mounts, interstage connections, payload shroud, and external body were carried out to determine both strength and weights requirements. Details may be found in the final report. ${ }^{2}$

\section{Airplane Stability \& Control}

Stability and control calculations are based on semiempirical methods. ${ }^{4}$ Longitudinal stability calculations focused on three areas. First, the airplane must be able to rotate about its main gear for take off. This did not size the horizontal tail. It did, however, size the elevators. Second, the airplane must be trimmable during cruise. Last, the airplane must meet a static margin requirement during cruise. The third criteria sized the horizontal tail. Ideally, the tail would be positioned such that all three criteria would be met simultaneously. This is not the case with the Eclipse and the tails are therefore larger than they might otherwise be. This is acceptable since the shorter fuselages which are associated with the larger tail allow for a shorter landing gear to meet the tip over and rotation requirements. Also, fuselage weight and tail weight are almost an equal trade off so there is a minimal weight penalty associated with the larger tail surface with shorter fuselages.

Take off rotation and trim calculations were estimated by summing the moments acting on the airplane. In the first case, by summing around the median point of the main gear contact points and in the second case by summing around the center of gravity. The landing trim requirement was not evaluated. Static margin calculations are done through the use of an x-plot. The design is for five percent static margin. This value was chosen as a point where there is sufficient margin for safe pilot control without making the tails extremely large. With only a five percent static margin, a stability augmentation system will be necessary to ensure controlled operations of the airplane. Static margin at take off is high due to the large tails needed for an acceptable static margin at cruise.

The critical condition for lateral and directional stability and control is a one engine inoperative condition on take off. This criteria sized the vertical tails. The two engine inoperative condition was also analyzed. Meeting the two engine out criteria required either a very high speed or excessively large vertical tails to maintain control. Since meeting this criteria would be detrimental to airplane performance, the one engine out condition was selected as the design condition.

\section{Booster Guidance, Navigation, and Control}

The launch team must be able to keep track of the Gryphon's position, velocity and acceleration in order to determine what attitude controls need to be implemented. The following choices have been made:

Mission Control. The Gryphon will utilize the existing ground support infrastructure of Pegasus.

Telemetry, Tracking, and Command. The telemetry tracking and command (TTC) services from the Eastem and Western Space and Missile Centers with be used.

Inertial Measurement Unit. Inertial reference is supplied by the strapdown inertial measurement unit (IMU), consisting of integration gyroscopes, linear accelerometers, and sensor electronics. The Litton LR-81 system will be used.

Global Positioning System Receiver. The Trimple Quadrex GPS Receiver was chosen.

Launch Panel Operator. One additional crew member aboard the Eclipse will be needed to monitor the Gryphon's systems before and immediately after launch.

On Board Computer. The onboard computer system interfaces with the subsystems and determines the course of action that they should take.

Gimbaled engines are the main source of attitude control; however, passive aerodynamic characteristics were used during the drop phase

\section{Airplane Performance}

Airplane performance was calculated for three mission scenarios: the normal launch mission, the minimum fuel mission, and the ferry mission. The minimum fuel mission consists of a climb to maximum altitude, loiter, launch, and descent. The lack of fuel for the cruise portions results in a higher launch altitude. The ferry 
mission consists of flying the maximum distance possible with the empty space booster.

The calculations for the two launch missions assume a launch abort at the last possible moment, which is the worst case scenario due to the extra drag and weight of the booster which is attached for the return portion of the mission. Calculations were based on analytical models of airplane performance. 10 Upon launch, a minimum radius turn is conducted at constant altitude. This maneuver should give maximum separation between the vehicles in a given amount of time.

Take off and landing distances are the distance to clear a 35 foot obstacle from or to a complete stop, respectively. The final values for this analysis are presented in Table 4.

Table 4 Design mission performance

\begin{tabular}{lr}
\hline Take off distance & $4,300 \mathrm{ft}$ \\
Landing distance & $3,400 \mathrm{ft}$ \\
Launch altitude & $43,300 \mathrm{ft}$ \\
Launch tum load factor & $2.2 \mathrm{~g}$ \\
Launch turn radius & $9200 \mathrm{ft}$ \\
Mission time & $6 \mathrm{hr} 55 \mathrm{~min}$ \\
\hline
\end{tabular}

\section{Airplane Subsystems}

Various subsystems of the airplane are now briefly described.

Landing Gear. The landing gear is a quadracycle configuration. This layout allows for all six gear trucks to fully retract into a fuselage without interfering with the payload. The main gear consists of four struts, each with an eight wheel landing gear truck in a dual-twin-tandem configuration. Each nose gear is steerable and has three wheels in a triple configuration. The main gear retract forward and aft and the nose gear retracts aft.

The main gear are located such that the airplane can rotate about the median point between the trucks by extending one shock absorber and compressing the other. The struts are long enough to ensure that the airplane meets all clearance and tip-over requirements. The nose gear are located so that a sufficient amount of the airplane weight rests upon it to allow for effective steering.

Hydraulic System. A conventional hydraulic system is employed. It operates at a pressure of 5,000 psi. This was chosen as a compromise between volume and weight requirements of a lower pressure system and the sealing requirements of a higher pressure system. In addition, the $5,000 \mathrm{psi}$ system is the standard used on large commercial transports today.
For safety, four levels of redundancy are employed with each of the primary flight control surfaces (aileron, rudder, and elevator) with each section of the control surface powered by three separate systems. Secondary control systems employ only two levels of redundancy. The high level of redundancy is called for since only two airframes are being built and any hull loss would be devastating to the program.

Electrical System. The electrical system for the Eclipse is sized using the requirements of an airplane of similar dimensions, the Boeing 747. This is done because the actual electrical loads of the systems are not known until a more detailed design for the airplane systems is carried out.

Three engine driven generators are used for normal airplane operations. There is an extra generator connected to the auxiliary power unit and an emergency generator connected to a free-fall ram air turbine. Batteries are incorporated into the system to maintain DC system voltage under transient conditions, to supply power for short term heavy loads, and to supply power in an emergency. In addition, there is a ground connection point for ground operations.

Flight Control System. A mechanical signaling system is used for the flight controls in this aircraft. All flight controls are irreversible. A mechanical signaling system was chosen, despite the weight penalty and higher maintenance, to avoid the cost and difficulty associated with the development of either a fly-by-wire or fly-bylight control system.

Two separate mechanical systems are employed for redundancy with the primary flight controls, while the secondary controls use only one level of redundancy.

Fuel System. The fuel system has a capacity of 260,000 pounds in the primary tanks. This value is a direct result of the performance calculations for the design mission. In addition, there are auxiliary tanks with a capacity of 90,000 pounds which brings total fuel capacity to 350,000 pounds. This extra fuel volume is used when ferrying the airplane, either with or without the payload, from place to place. All tanks are located in the outboard section of the wing between the first and third spars.

Pumps are sized for one and a half times the maximum fuel flow. The pumps have a through flow of $\mathbf{4 7 3}$ pounds per minute. The lines are two inches in diameter. Surge tanks are located outboard of the main tanks.

In order to keep the center of gravity of the fuel constant, several fuel cells are used with flow valves and pumps which are computer controlled to maintain a constant center of gravity. 
Crew Issues. The crew of the Eclipse consists of three people, the pilot, copilot, and a launch officer. The crew are in the forward section of the left fuselage in a pressurized compartment. The pilot and copilot are on a raised platform to enhance visibility with the launch officer behind them. A galley and lavatory are also provided for crew comfort during the mission.

A ground based simulator is needed for this airplane to maintain pilot proficiency. Since this airplane will only be used once every other month for missions, the pilots need other flight time to remain proficient. This could be attained through use of the airplane itself for training, but this risks loss of the airplane. Instead a six degree of freedom trainer could be used to train the pilots for flight and to keep them proficient in the airplanes flight qualities. One other option is available for training, the flying simulator. This concept was rejected due to the cost associated with maintaining the aircraft.

\section{Payloads}

The system was designed to meet the following criteria:

- Delivery of $7,900 \mathrm{lb}$, including the payload support structures, to GTO

- Delivery of $17,000 \mathrm{lb}$, including the payload support structures, to LEO

- Maximizing of usable payload envelope

- Capability of multiple satellite deplooyments to both GTO and LEO

- Compatibility of delivering Space Station Freedom (SSF) resupply packages

The GTO delivery limit will allow the booster to carry a large majority of existing commercial communication satellites. The LEO capability will allow for the delivery of scientific satellites and resupply packages to a space station. The payload bay dimensions are compatible with currently planned SSF payload packages which are 15 feet in diameter and 10 to 15 feet in length. Communications satellites cover a large range but many are 7 to 10 feet in diameter and 8 to 12 feet in length. Single, double, and, possibly, triple stacked payloads can be accommodated.

\section{Thermal Control}

Thermal control of the Gryphon is concerned primarily with the external structure and the avionics bay. The external structure uses ablative coating during the ascent of the booster. The avionics bay uses a multi-component system including a helium purge, a heat sink radiator, enamel coatings, and multilayer insulation.

\section{Gryphon Assembly and Integration}

The system used to put the Gryphon together and attach it to the Eclipse include:

- Gryphon assembly building (GAB)

- Transportation and attachment of completed booster

- Attachment of Gryphon to Eclipse

Provision is made for two parallel assembly lines. The schedule calls for up to one vehicle every two weeks, or two vehicles in close succession if launch windows require it.

Once assembled and check out a transportation trailer takes the Gryphon to the Eclipse. It is capable of moving the Gryphon so that attachment points line up. Once correct alignment is achieved the hydraulic interface mechanism will close and securely attach the Gryphon to the Eclipse.

The location of the facility was based on the availability of rocket fuels on site, proximity to the equator for GTO launches, distance from large population centers, and the availability of a 10,000 foot runway.

The interface mechanism has eight attachmentment points located on the second stage of the booster, symmetric about the center of gravity.

\section{Cost Analysis}

The airplane cost analysis was performed using empirical methods. 11 The price was determined in 1993 dollars. Since only two airplanes are being built and the weight of the Eclipse is so large, the precision of these values remains uncertain.

The cost to acquire the two airplanes is estimated at $\$ 1.72$ billion. This includes all costs associated with the design, testing, manufacturing, flight testing, profit, and financing. This cost is much higher than buying an airplane such as the Boeing 747 , but this is due to the small number of planes over which the development cost is spread.

The cost of the Gryphon was determined by the known cost of existing components such as the engines and propellant tanks and the estimated cost of standard construction techniques used for new components such as the payload shroud and main body. The cost of the Gryphon is estimated at \$22.1 million per copy.

Throughout this design study a primary goals was to develop a system that could provide investors with a $15 \%$ return on their money. Every decision, consistent with the safety and integrity of the project, was made to try to 
achieve a launch cost $50 \%$ below the chief competitors. This would leave $50 \%$ for financing, insurance, profits and competitive pricing.

The direct cost per mission for a 60 mission life time is an estimated $\$ 28$ - 30 million. This includes the expendable booster and the operating costs. When the initial cost of the Eclipse is spread over 60 missions the total launch cost rises to over $\$ 50$ million. A higher number of missions could lower this cost substantially. This increased number of missions could be accomplished in several ways: by increasing the number of missions per year, by lengthening the life span, or by finding alternate uses for the airplane. Finding alternate uses would be a last resort since it risks loss of the airframe.

The cost estimates in the two final reports show some differences; they had not yet converged when the deadline (end of the term) was reached; however, by all estimates the cost per pound to orbit, which is $\$ 6200$ for the 7,900 lb payload to GTO, is competitive with existing launch systems and has sufficient margin to cover intangibles and make a profit for investors. Unfortunately, the initial cost of producing the airplanes requires such a large up front investment that it may make the program infeasible.

\section{Wind Tunnel Testing}

A 1:120 scale model of the Eclipse was tested in the University of Michigan $5{ }^{\prime} \times 7^{\prime}$ subsonic wind tunnel. The model was tested with and without the Gryphon attached. The tunnel was run at two speeds, 120 and 150 miles per hour. This data was then scaled to $\operatorname{Re}=39.4 \times 10^{6}$ for comparison with the analytical data.

The clean predicted and test drag polars are similar. Unfortunately, due to the scale of the model, there was very bad interference between the Gryphon and the Eclipse. This led to a much worse zero lift drag for the model than was anticipated. Due to the low speed of the test, the assumption of zero angle of attack for the payload was not valid. The model lift curve slope, however, is in good agreement with the analytical value.

\section{Conclusion}

A design has been presented outlining an airborne launch vehicle and associated large air launched space booster. The airplane has a twin fuselage layout for payload and landing gear integration. The wing has a high aspect ratio for increased altitude performance. The three stage booster is of conventional configuration and design. This design meets or exceeds all of the goals which were set at the start of the design process.

The propulsion, aerodynamics, structures and weights, stability and control, and performance analysis methods used in designing this system have been outlined. The payload integration, landing gear, hydraulic, electrical, flight control, fuel, and crew systems designed for the Eclipse have also been outlined. In addition, the results of wind tunnel testing have been presented and discussed.

It is technologically feasible to design an aircraft which can carry an 500,000 pound air launched space booster to an altitude over 40,000 feet and launch it. The stumbling block, however, is the initial cost associated with acquiring the airplanes. The per mission cost can be made reasonable, if a large enough number of missions is flown.

\section{Acknowledgments}

Following the references is a complete list of students, teaching assistants, and faculty who contributed to this project. Other persons who contributed are acknowledged in the two final reports.

\section{References}

1 Poth, S.M., Jr., et al., Design of an Airborne Launch Vehicle for an Air Launched Space Booster, University of Michigan, Ann Arbor, Mich., July 1993.

2 Fisher, M.A., et al., Project Gryphon: Air Launched Space Booster, University of Michigan, Ann Arbor, Mich., June 1993.

3 Lewis, R.J., Sr., Big Engine Data, General Electric Aircraft Engines, Evendale, Ohio, Unpublished, Nov. 16, 1992.

4 Roskam, J., Airplane Design Part VI: Preliminary Calculation of Aerodynamic. Thrust, and Power Characteristics, Roskam Aviation and Engineering Corp., Ottawa, Kansas, 1989.

5 Berry, D.L., Civil Aircraft Propulsion Integration: Current and Future, Boeing Commercial Airplane Company, Seattle, Wash., Unpublished, Nov. 12, 1992.

6 Harris, C.D., "Aerodynamic Characteristics of a 14Percent-Thick NASA Supercritical Airfoil Designed for a Normal-Force Coefficient of 0.7," NASA-Langley Research Center, Hampton, Virginia, NASA TM X72712, July 1975.

7 Bengelink, R., Boeing Commercial Airplane Co., Seattle, Wash., Personal Conversation, Feb. 1993.

8 Roskam, J., Airplane Design Part V: Component Weight Estimation, Roskam Aviation and Engineering Corp., Ottawa, Kansas, 1989.

9 Udin, S.V., and Anderson, W.J., "Analytical Method for Wing Mass Calculation of Twin Fuselage Aircraft," Journal of Aircraft, Vol. 29, Sept.-Oct. 1992, pp. 907914.

10 Vinh, N.X., Aerospace 440 Vehicle Systems Performance Unpublished Lecture Notes, University of Michigan, Ann Arbor, Mich., Jan.-May 1993. 
11 Roskam, J., Airplane Design Part VIII: Airplane Cost Estimation: Design, Development, Manufacturing. and Operating, Roskam Aviation and Engineering Corp., Ottawa, Kansas, 1989.

\section{Class Roles}

\section{AE 481. Airplane Design}

Faculty: David W. Levy

Graduate Teaching Assistant: John Blow

Students:

Maize Team

Team Leader. Rich Choi

Assistant: Michael Fisher

Aerodynamics group: Kevin McGuirk

Robert Mitchell*

Thuc Nguyen

Structures and Stephen Battle*

Weights group: Guan Soh

Matthew Wagner

Stability and Benjamin Place

Control group: $\quad$ Tracy Scott*

$\begin{array}{ll}\begin{array}{l}\text { Propulsion } \\ \text { Integration group: }\end{array} & \begin{array}{l}\text { Frank Gulczinski* } \\ \text { Robert Jorden } \\ \text { Charla Widmer }\end{array} \\ \text { Systems } & \begin{array}{l}\text { Chin Chao } \\ \text { Integration group: }\end{array} \\ & \begin{array}{l}\text { Enrique Garcia } \\ \text { Scot May } \\ \text { Matthew Taylor* } \\ \text { Ryan Waddington }\end{array}\end{array}$

Blue Team

Team Leader: Stefan Poth

Assistant: Jack Kobus

Aerodynamics group: Brian Dumont*

Jeffrey Felkowski

Cynthia Tarr

$\begin{array}{ll}\begin{array}{l}\text { Structures and } \\ \text { Weights group: }\end{array} & \begin{array}{l}\text { Rolf Kappe* } \\ \text { Kevin Kilburn } \\ \text { Rance Stehouwer }\end{array} \\ \begin{array}{ll}\text { Stability and } \\ \text { Control group: }\end{array} & \begin{array}{l}\text { Michael Ol* } \\ \text { Sarah Lewis }\end{array} \\ \begin{array}{l}\text { Propulsion } \\ \text { Integration group: }\end{array} & \begin{array}{l}\text { Kevin Williamson* } \\ \text { Bilal Rathur }\end{array}\end{array}$

Systems

Scott Cohen

Integration group: Brett Deutscher

Andrew Flotten

Mauricius Gibin

is... Brian Nehez

AE 490/590. Advanced Airplane Design

Faculty: David W. Levy

Graduate Teaching Assistant: John Blow

Students:

\section{AE 483. Space System Design}

Faculty: Joe G. Eisley

Graduate Teaching Assistant: James Akers

Students:

Project leader. Lyon King

Assistant project leader: Michael Fisher

Payload team: Christopher Bernard

James Dice

Karina Jacobson*

Craig Litherland

Kevin Whalen

Mission Analysis: Richard Draper

Sean Fifield

Scott Mullison

Alan Ristow*

Vincent Wiltse

Propulsion:

Krista Campbel1*

Chad Hoggard

Adam Nagaj

Bilal Rathur

John Vandenberg

Structures: $\quad$ Scott Huggins

Joseph Ruddy*

Wolfgang Schubert

Ronald Shimshock

Philip Wojcik
Mission Control
Kah-Wai Aw
and Communications:
Scott Egbert*
Brian Smith
Christopher Yee 
Power and Thermal: Joshua Baron Thomas Godfroy

Kevin Kilburn

Josef Regner*

Romy Sharieff

Spacecraft Integration: Timothy Ballew

David Cortwright

Elizabeth Hilbert*

Todd Mueller

Daniel Potter

Aircraft Interface: Jonathan Albert

Michael Hindley*

Adam Koziel

Christopher Vegter

*Team leader 